\title{
Unresectable Gastric Carcinoma
}

National Cancer Institute

\section{Source}

National Cancer Institute. Unresectable Gastric Carcinoma. NCI Thesaurus. Code C159775.

A gastric carcinoma that is not amenable to surgical resection. 